«Філософія та політологія в контексті сучасної культури», 2018, Т.10. №1-2 (22)

УДК: 1 (091); 141

Received 11 July 2017

Received in revised form 15 August 2017

Accepted 13 September 2017
Снитько Д.Ю.

Дніпропетровський національний університет залізничного транспорту імені академіка В. Лазаряна e-mail:dimanche82@gmail.com

ORCID 0000-0001-7417-7958

\title{
О НАЧАЛАХ ДРЕВНЕГРЕЧЕСКОЙ ФИЛОСОФИИ:
}

\section{П. АДО И Ф. НИЦШЕ}

Резюме. Статья представляет собой попьтку осмысления концепиии природы, представленной в творчестве Пьера Адо. Основное внимание уделено раскрытию сущности двух основных начал в европейской культуре - «прометеевского» и «орфеевского». Данные начала противостоят у Адо как научно-техническое и созериательно-эстетическое понимание природы. Методология. Для раскрытия особенностей понимания данной проблемы Пьером Адо используется компаративный метод и концепция франиузского мыслителя сопоставляется с нициеанской конщепщией о наличии «дионисийского» и «аполлонического» начал в культуре Античности. В результате исследования показано, что осмысление оснований античной культуры у Ф. Ницще и П. Адо исходит из единого представления о противостоянии в культуре эстетического и рачионального начал и доминировании 6 последующей европейской культуре именно рачионалистической традиции. Оба мыслителя считают такой подход противоположным самой сущцности природы. Но, в то же время, принципиальным моментом, в котором Ницще и Адо расходятся, является общая оценка человеческого разума. Ницше - радикально негативно настроен к разумности, в то время как Пьер Адо именно созериательную рациональность считает одной из адекватных форм человеческого отношения к природе.

Ключевые слова: Пьер Адо, Фридрих Нищче, природа, человек, «орфеевское», «прометеевское», «дионисийское», «аполлоническое».

Снітько Д.Ю., Дніпропетровський національний університет залізничного транспорту імені академіка B. Лазаряна, e-mail: dimanche82@gmail.com

Про начала давньогрецької філософії: П. Адо і Ф.Ніцше.

Резюме. Мета дослідження. Стаття $\epsilon$ спробою осмислення концепџї природи, представленоїв творчості Пьера Адо. Основна увага приділена розкриттю суті двох основних начал в європейській культурі - «прометеївського» $i$ «орфеївського». Дані начала протистоять у Адо як науково-технічне і споглядально-естетичне розуміння природи. Методологія. Для розкриття особливостей розуміння зазначеної проблеми Пьером Адо використовується компаративний метод $і$ концепція франиузького мислителя зіставляється з ніцчеанською конщепиією про наявність «діонісійського» $i$ «аполонійського» начал в культурі Античності. В результаті дослідження показано, щзо осмислення підвалин античної культури у Ф. Ніџще і П. Адо починають з єдиного уявлення про протистояння в культурі естетичного і раціонального начал і визнання домінування в подальшій європейській культурі саме рачіоналістичної традииї. Обидва мислителі вважають такий підхід протилежним до самої суті природи. Але, в той же час, принщиповим моментом, в якому Ніцще і Адо розходяться, $\epsilon$ загальна оцінка людського розуму. Ніџще - радикально негативно налаштований до розумності, тоді як Пьер Адо саме споглядальну раціональність вважає однією з адекватних форм людського відношення до природи. 
Ключові слова: Пьєр Адо, Фрідріх Нічฺще, природа, людина, «прометеївське» $i$ «орфеївське», «діонісійське» $i$ «аполонійське».

Snitko D. Y., Dnipropetrovsk National University of Railway Transport named after Academician V.Lazaryan, e-mail: dimanche82@gmail.com

\section{About the beginning of Ancient Greek Philososophy P. Hadot and F. Nietzshe}

Abstract. The purpose of the article is an attempt to comprehend the concept of nature, presented in the works of Pierre Ado. The main attention is paid to revealing the essence of two main principles in European culture - «Prometheus» and «Orphan». Data begins to confront Ado as a scientific, technical and contemplative-aesthetic understanding of nature. Methodology. To reveal the peculiarities of understanding this problem, Pierre Ado uses a comparative method and the concept of a French thinker is compared with the Nietzschean concept of the presence of the "Dionysian" and "Apollonical» principles in the culture of Antiquity. As a result of the study, it is shown that the understanding of the foundations of ancient culture in F. Nietzsche and P. Ado begins with a single idea of confrontation in the culture of aesthetic and rational principles and recognition of the domination in the further European culture is precisely rationalist tradition. Both thinkers consider such an approach to the very nature of nature. But, at the same time, the fundamental point in which Nietzsche and Ado diverge is the general assessment of the human mind. Nietzsche is radically negatively minded, while Pierre Ado sees contemplative rationality as one of the adequate forms of human attitude toward nature.

Key words: Pierre Hadot, Friedrich Nietzsche, nature, man, «Prometheus» and «Orphic», «Dionysian» and «Apollonian».

Актуальность. Пьер Адо - известный французский филолог и философ, переводчик и глубокий комментатор античной философии. Творчество Пьера Адо было устремлено к исследованию античной культуры и ее проблем. Неординарность в переосмыслении идей древнегреческой и древнеримской философии Пьером Адо способствовали влиянию его идей на ряд мыслителей XX века, в частности на М. Фуко.

Необходимость обращения к идеям Пьра Адо, более глубокому их осмыслению связана с тем, что в своем творчестве мыслитель пытался показать глубокую связь философии с проблемой самого человека, его духовности. Именно поэтому Адо считал занятия философией «духовными упражнениями». Актуальность идей французского философа связана как с современным положением человека (проблематичность которого выражена в постмодернистском тезисе о «смерти человека»), так и с кризисными явлениями в современной европейской культуре. Последний аспект во многом обусловлен новоевропейской мировоззренческой установкой на подчинение природы человеку.

В связи с этим, данная статья представляет собой попытку осмысления концепции природы, представленной в работе Пьера Адо «Покрывало Исиды: Эссе по истории идеи Природы», которая вышла в 2004 году во Франции и посвящена пониманию природы и отношению к ней человека от Античности до современности.

Обзор литературы. Изучению идей Пьера Адо на постсоветском пространстве было уделено весьма скромное внимание. Впрочем, следует отметить работы А.А. Ткаченко, П.А. Гаджикурбановой, М.А.Гарнцева, П.Б. Михайлова, В.П. Визгина, в которых, впрочем, не уделяется внимания пониманию природы Пьером Адо. Среди иностранных авторов количество исследований посвященным философии Пьера Адо намного больше; среди них можно назвать таких авторов как A. Fagot-Largeault, M. Montanari, A. I. Davidson, F. Worms и других. 
«Філософія та політологія в контексті сучасної культури», 2018, Т.10. №1-2 (22)

В целом, проблемы понимания природы в творчестве французского мыслителя остаются не раскрытыми, что актуализирует данное исследование.

Цель и задачи исследования. Цель статьи состоит в том, чтобы выявить основные положения природной концепции Пьера Адо в контексте его обращения к европейской философской традиции. В связи с этим возникают следующие задачи: 1) раскрыть смысл «прометеевского» и «орфеевского» понимания природы у П. Адо; 2) провести сравнительный анализ понимания основных движущих начал европейской культуры у П.Адо и Ф.Ницше; 3) выявить основные преимущества концепции природы П. Адо.

Основные результаты исследования. Свои размышления П. Адо начинает с анализа высказывания античного мыслителя Гераклита Эфесского: «phusis kruptesthai philei», которое часто переводят как «Природа любит прятаться». Таким образом, основной темой размышлений Адо становится именно Природа и ее восприятие в античной и европейской культуре, a также способы отношения к ней. Сам тезис Гераклита французский мыслитель оценивает, как весьма глубокий и неоднозначный, доказательством чему служит попытка П. Адо объяснить всю последующую философию и культуру как раскрытие приведенной мысли античного автора.

Адопытаетсяпроникнутьвсмыслизречения Гераклита и анализирует каждое из понятий. Так, philein (любить) у греков часто означало не столько чувство, сколько «склонность к чемулибо», а phusis понимается и как «природа» и как «рождение». В итоге, философ приходит к выводу, что понимать данное выражение следует как «природа (в смысле собственного устройства, собственной сильи, бытия вещии) любит прятаться, не быть видимой». Тем самым формируется тема сокрытого, того, что лишь едва приоткрывается.

Но, в то же время, П. Адо замечает, что данное выражение может быть истолковано и в ином контексте. Phusis можно понимать именно как «рождение», а kruptesthai - как «смерть, исчезновение». В таком случае, выражение Гераклита имеет следующий смысл: «То, что порождает, стремится уничтожить». Кроме того, Адо приводит 5 возможных способов понимания изречения Гераклита, но настаивает именно на приведенном выше значении как наиболее правильном и отвечающем диалектическому духу философии Гераклита [1, с. 20-21].

Пьер Адо, анализируя понимание природы в Античности, стремится исследовать развитие этих представлений в европейской философии. В частности, указание Гераклита на то, что природа любит прятаться, обретая покрова таинственности и недоступности, находит свое место, например, в философии M. Хайдеггера, который указывает, что слово «истина» и «бытие» находятся в одном семантическом поле, а само понятие «истина» - греческое «алетейя» - означает не что иное как «не-сокрытось», то есть открытие того, что было сокрыто, утаено.

Пьер Адо также принимает подобное отождествления природы и истинь и настаивает на античном понимании истины не просто как соответствии мысли о вещзи и самой вещчи, а как самой природе (однако, полного отождествления и бытия Хайдеггером Адо не разделяет). Именно познание природы, открытие истины П. Адо и называет метафорично «снятием покрывала Изиды». Таким образом, если истина и природа совпадают, то стремление к истине есть ничем иным как стремлением к природе.

Здесь следует заметить, что познание истины у греков рассматривалось не только, как цель сама по себе, но и в контексте сопричастности человека истине, того влияния, которое истина оказывает на познающего. Иными словами, вопрос состоит в том, как истина преобразует человека (или - как природа трансформирует человека?). Познающий истину, стремящийся к мудрости, должен понимать данное обстоятельство. Именно поэтому у П. Адо познание истины связано с «духовными упражнениями» 
субъекта по отношению к самому себе (у М. Фуко более конкретно эта мысль выражена в концепте «заботы о себе»). Таким образом, познание истины, приоткрытие тайн природы, которой сопричастен человек, является не чем иным, как заботой о себе: познание природы необходимо не для властвования над ней, а для ответа на вопрос «как мне быть?».

П. Адо указывает на то, что уже в Античности сформировалось два основных подхода в понимании природы и отношения к ней. Первая установка (ее становление Адо связывает с философией Сократа) исходит из представления о природе как такой, которая не просто любит прятаться, а вообще трудно доступна для человека, а потому нет никакой необходимости в занятиях физикой - наукой о природе. Вторая установка (по мнению Адо, явно прослеживается уже у Антиоха Аскалонского, который жил во II-I веках до н.е.), связана как раз с убеждением в возможности раскрытия тайн и сущности природы [1, с. 118, 119].

Корень различия приведенных позиций Адо усматривает в способах соотнесения природы и человека. В первом случае доминирует представление о единстве человека и природы, отсутствии самого противопоставления субъект-объект, в котором реализуется познание природы. Вторая установка исходит как раз из противопоставления природы и человека, природа представляется чемто чуждым и даже враждебным человеку, а потому требует познания для дальнейшего умиротворения (подчинения).

Наиболее ярко различие двух способов восприятия природы, по мнению П. Адо, прослеживается в понимании сущности и цели искусства в широком смысле: установка враждебности по отношению к природе ведет к возникновению науки и техники; установка на единение с природой ведет к возникновению и развитию искусства, как продолжения самой природы и носит выраженный созерцательный характер.

Таким образом, Пьер Адо выделяет два основных принципиальных подхода к природе в античной (а позже - и в европейской) культуре, которые метафорически определяет, как «прометеевскую» и «орфеевскую» установки.

«Прометеевская» установка в отношении природы состоит в использовании технических процедур для познания природы с целью властвования над ней $[1$, с. 130]. В античной культуре данная установка имела три основных формы: механика, магия и некоторые элементы экспериментального исследования.

Данную установку Адо критикует, опираясь на историю философии, в частности вспоминает платоновскую традицию, в рамках которой познание природы не являлось чемто необходимым, да и само познание имело скорее гипотетический характер, нежели требовало полного соответствия знания и бытия. В самой древнегреческой мифологии существует достаточно предостережений по поводу подобного отношения к природе. В мифах о Прометее (который как раз и дал, согласно мифу, людям огонь и знания о ремеслах) и Икаре явно прослеживается указание на опасность упрямого стремления к овладению тайнами природы, относящихся к сфере божественного [1, с. 181].

Падение человеческих обычаев и нравов якобы закономерно приводит к возникновению и разрастанию человеческих пороков алчности, эгоизма, чувственных наслаждений, которые невозможно удовлетворить исчерпывающе. Именно в связи с подобной «порчей» человека и связано его стремление властвовать над природой, которое и представляется как способ удовлетворения безграничной человеческой алчности.

С такой точки зрения то, что сегодня именуют прогрессом предстает ничем другим, как упадком и деградацией человечества. В постоянной погоне за материальными обретениями, которые может предоставить природа, человек уже не мыслит созерцательно, а лишь непрерывно чего-то желает, что-то планирует и постоянно беспокоится. 
«Філософія та політологія в контексті сучасної культури», 2018, Т.10. №1-2 (22)

В противоположность «прометеевской» установке П. Адо указывает на установку «орфеевскую» (идущую якобы от Орфея, древнегреческого

мифологического персонажа, который олицетворял силу искусства). Эта установка предстает как «метод, который пытается раскрыть тайны природь без использования инструментов, опираясь на восприятие, используя возможности философского и поэтического дискурса, а также живописи» [1, с. 201].

«Орфеевская» установка по отношению к природе рассматривает познание мира как созерцание. Познание есть, скорее «духовное упражнение», нежели стремление к окончательному и исчерпывающему описанию мира. Познание природы приносит удовольствие, поскольку оно представляется игрой, цель которой - отгадывание загадок [1, c. 239].

Таким образом, в общем смысле, в «орфеевском начале» П. Адо усматривает два способа отношения к природе и ее познанию - рациональный (философ) и эстетический (художник) пути, которые являются наиболее оправданными и соответствующими самой природе. Именно названные способы отношения к природе и оправдывает Пьер Адо.

Мысли Адо, представленные в его книге «Покрывало Изиды», во многом сходны с идеями других известных философов, таких как А. Шопенгауэр, Ф. Ницше, М. Хайдеггер, чего сам Адо не скрывает, постоянно упоминая имена этих и других мыслителей. Само произведение П. Адо представляет собой историко-философское исследование, целью которого в частности и является выявление определенных тенденций в процессе развития философского знания.

Совершенно очевидно, что с точки зрения историко-философского исследования работа Пьера Адо «Покрывало Изиды» имеет большую ценность, поскольку развитие и эволюция «прометеевского» и «орфеевского» начал прослеживается автором внимательно и скрупулезно со всей необходимой глубиной и проницательностью.

Некоторые авторы в качестве недостатка данного произведения П. Адо считают ее наукообразность и апологию рациональных способов познания мира (оправдание у Адо философско-эстетического восприятия) и одновременное игнорирование таких источников знания, как мистическое прозрение и откровение [3]. Однако, есть основания полагать, что данная критика связана с особой заинтересованностью определенных авторов именно вопросами религиозного осмысления мира.

Таким образом, концепцию П. Адо о существовании в европейской культуре двух мировоззренческих установок, описывающих взаимоотношения человека и природы можно считать вполне оригинальной и заслуживающей внимания. Особенно ценным представляется положение об определенном единстве рационально-созерияательного и созериательно-эстетического понимания природы.

Наличие двух, в определенном смысле, противоположных начал в культуре Античности констатировал и Фридрих Ницше. По его мнению, в недрах древнегреческой культуры можно выделить «аполлоническое» и «дионисийское» начала, восходящие в своей сущности к образам греческих богов Аполлона и Диониса.

Аполлоническое начало - это стремление к гармонии, мере, разумности, красоте и индивидуальности. Дионисийское неудержимое, неразумное, страстное, неумеренное, стремящееся размыть рамки индивидуального. Говоря словами Ницше, аполлоническое - это спокойное созерцание, а дионисийское - опьянение.

В контексте осмысления проблемы понимания природы важен именно тот момент, в котром аполлоническое предстает как основа субъекта, а дионисийское как его преодоление. Иными словами, аполлоническое, как основанное на разуме, создает противопоставление мыслящего субъекта и объекта-природы, ведь само 
рациональное познание предполагает наличие субъект-объектных отношений. Напротив, в основе дионисийского лежит безрассудность, забвение индивидуальности и слияние с окружающим миром, природой.

\section{Аполлоническое}

противостоит дионисийскомукакразумное-инстинктивному, как рассудительность - жизненному порыву. Дионисийское оказывается гораздо ближе к природе,посколькуприрода-иестьсамажизнь, хаотичная и безрассудная, инстинктивная и трагичная. Забвение дионисийского начала оборачивается забвением самой природы, самой жизни и именно в этом Ницше видит упадок человечества, его декаданс. Он говорит о необходимости возрождения трагедии, трагического мироощущения и трагического типа человека, для которых главным является ориентация на искусство, а не науку.

Согласно Ницше, именно вознесение аполлонического начала стало основой для возникновения европейской науки, но в то же время и положило начало упадка греческой культуры. В этом смысле одним из первых провозвестников этого упадка немецкий философ считает Сократа, который превознес разум и рациональную диалектику. Именно поэтому Ницше называет Сократа «типом упадка» [5, с. 759]

Культуру же, возникшую вследствие искусственного аполлонического начала и угнетения дионисийского Ницше, называет «сократической», либо же «александрийской», основывающуюся на разумности и вере в такую же логичность и познаваемость мира, природы. По мнению Ницше, аполлоническое и дионисийское начала имеют равнозначно важное значение для культуры и только забвение дионисийского приводит к общему упадку [4, с. 168].

Прометей у Ницше оценивается в качестве позитивного героя, который по собственной воле, мужественно приняв все возможные последствия для себя, совершил святотатство перед богами. Он предстает героем активным, который, не взирая на трагичность бытия, решается на поступок, пренебрегая расчетливостью рассудка. Одновременно Ницше обращается и к образу Эдипа, участь которого состоит в принятии жестокого наказания за попытку раскрыть тайны бытия: «тот, кто разрешает загадки природы, - той самой сфинги с ее двоякой натурой, - тот должен попрать и самый священный порядок природы, становясь убийцей отияа и супругом матери» [4, с. 113].

Ницше считает, что теоретизирование - иллюзия, как и рационализм, как и последующее христианство, как и оптимизм. И только трагические видение мира и осмысление жизни в художественных формах является более близким к самой сущности мира. Поэтому, «искусство - а не мораль - выставлено в качестве собственно метафизической деятельности человека...» $[4$, c. 55$]$.

Выводы. На основании проведенного исследования, сопоставляя версии П. Адо и Ф. Ницше, касающиеся оснований культуры Античности, являющейся фундаментом европейской культуры, можно сформулировать следующие выводы.

1. У обоих авторов проявляется критическое отношение к утилитарной ращиональности.

Однако существенное различие в оценке разумности человека как таковой не позволяет полностью отождествить позиции Ницше и Адо. Если у Ницше рациональность является чем-то искусственным, противостоящим самой сущности природы, то Пьер Адо настаивает на определенном единстве рационально-созерцательного и созерцательно-эстетического понимания природы. Для Ницше же такое понимание является неприемлемым, так как он четко противопоставляет эстетическое и разумное. Ницше предлагает принять трагичность бытия и оставить всякие попытки рационального переустройства мира с целью обеспечения человечеству спокойного существования.

2. Ф. Ницше и П. Адо весьма по-разному оценивают мифический образ Прометея. Если у Ницше Прометей - герой, который в 
«Філософія та політологія в контексті сучасної культури», 2018, Т.10. №1-2 (22)

своей попытке открыть людям тайны бытия, по собственной воле принимает трагическую судьбу, то у Адо образ Прометея предстает именно как попытка познания природы с целью властвовать над ней. Но, оба мыслителя соглашаются в том, что античная мифология однозначно указывает на опасность подобных намерений и их противоестественность.

3. Весьма различно отмеченные авторы оценивают вклад Сократа в развитие античной мысли. Для Ницше Сократ знаменует собою начало упадка греческой культуры, тогда как Адо расценивает сократическую традицию в качестве созерцательно-рациональной попытки осмысления человеком самого себя. Сократ призывал совсем не к познанию природы, а к заботе о собственной душе.

4. Помимо уже отмеченного существенное различие в позициях Ф. Ницше и П. Адо состоит еще и в том, что для Ницше человек - часть природы и потому не должен какимлибо образом противостоять ей, а должен, наоборот, существовать в соответствии с самой жизнью. Французский философ же исходит из сократического представления о том, что человек является особой формой бытия, способной к мышлению и духовной жизни. Именно эта особенность человека и ставит сам вопрос о том, как ему быть? Для Ницше ответ прост - человек часть жизни, а потому должен существовать по ее законам трагичности, страсти, инстинкта.

5. Осмысление оснований античной культуры у Ф. Ницше и П. Адо исходит из единого представления о противостоянии в культуреэстетического и рационального начал и доминировании в последующей европейской культуре именно рационалистической традиции. Оба мыслителя считают такой подход противоположным самой сущности природы, которая «любит прятаться», а потому оправдывают художественное, эстетическое видение мира. Но, в то же время, принципиальным моментом, в котором Ницше и Адо расходятся, является общая оценка человеческого разума. Ницше - радикально негативно настроен к разумности, в то время как Пьер Адо именно созерцательную рациональность считает одной из адекватных форм человеческого отношения к природе (наряду с эстетическим, «орфеевским» пониманием).

\section{Библиографические ссылки}

1. Адо, П. Покривало Ізіди. Нарис історії ідеї про Природу. Пер. з франц. О. Йосипенко. К., 2016. 470 c.

2. Михайлов, П.Б. Пьер Адо о философии природы, радости и ужасе бытия. Философия религии: альманах (2012-2013). М., 2013. С. 471-483.

3. Ницше, Ф. Рождение трагедии или Эллинство и пессимизм. Фридрих Нищще. Рождение трагедии; составление, общая редакция, комментарий и вступительная статья А.А.Россиуса. M., 1990. C. 47-158.

4. Ницше, Ф. Сумерки идолов или как философствуют молотом. Ницище, Ф. По ту сторону добра и зла: Сочинения. М., Харьков, 2006. С. 749-836.

5. Шопенгауэр, А. Мир как воля и представление. Шопенгауэр А. Афоризмы житейской мудрости; пер. с немецкого. М., СПб., 2005. С. 27-552.

6. Фаго-Ларжо, А. Философия как образ жизни. Памяти Пьера Адо. Bопросы философии. 2016. № 9. С. 198-210.

7. Гаджикурбанова П.А. «Духовные упражнения» или «забота о себе» (стоическая этика в интерпретации П.Адо и М.Фуко). ЭТИЧЕСКАЯ МЫСЛЬ. Выпуск 9. РАН, Институт философии. С. 27-42.

8. Гарнцев М.А. Пьер Адо и его подход к античной философии. Адо П. Что такое античная философия / Пер. с фр. В.П.Гайдамака. М., 1999. 
9. Визгин, В.П. Пьер Адо и экзистенциальная философия. Философские науки. 2011. № 11. C. 91-97.

10. Визгин, В.П. Пьер Адо о «Трагедии философии» Булгакова. Bопросы философии. 2009. № 7. С. 153-157.

\section{References}

1. Ado, P. Pokrivalo Izidi. Naris IstorIYi IdeYi pro Prirodu. Per. z frants. O. Yosipenko. K., 2016. $470 \mathrm{~s}$.

2. Mihaylov, P.B. Per Ado o filosofii prirodyi, radosti i uzhase byitiya. Filosofiya religii: almanah (2012-2013). M., 2013. S. 471-483.

3. Nitsshe, F. Rozhdenie tragedii ili Ellinstvo i pessimizm. Fridrih Nitsshe. Rozhdenie tragedii; sostavlenie, obschaya redaktsiya, kommentariy i vstupitelnaya statya A.A.Rossiusa. M., 1990. S. 47158.

4. Nitsshe, F. Sumerki idolov ili kak filosofstvuyut molotom. Nitsshe, F. Po tu storonu dobra i zla: Sochineniya. M., Harkov, 2006. S. 749-836.

5. Shopengauer, A. Mir kak volya i predstavlenie. Shopengauer A. Aforizmyi zhiteyskoy mudrosti; per. s nemetskogo. M., SPb., 2005. S. 27-552.

6. Fago-Larzho, A. Filosofiya kak obraz zhizni. Pamyati Pera Ado. Voprosyi filosofii. 2016. № 9. S. 198-210.

7. Gadzhikurbanova P.A. «Duhovnyie uprazhneniya» ili «zabota o sebe» (stoicheskaya etika V interpretatsii P.Ado i M.Fuko). ETIChESKAYa MYiSLb. Vyip. 9. RAN, Institut filosofii. S. 27-42.

8. Garntsev M.A. Per Ado i ego podhod k antichnoy filosofii. Ado P. Chto takoe antichnaya filosofiya / Per. s fr. V.P.Gaydamaka. M., 1999.

9. Vizgin, V. P. Per Ado i ekzistentsialnaya filosofiya Filosofskie nauki. 2011. № 11. S. 91-97.

10. Vizgin, V. P. Per Ado o «Tragedii filosofii» Bulgakova. Voprosyi filosofii. 2009. № 7. S. $153-$ 157. 